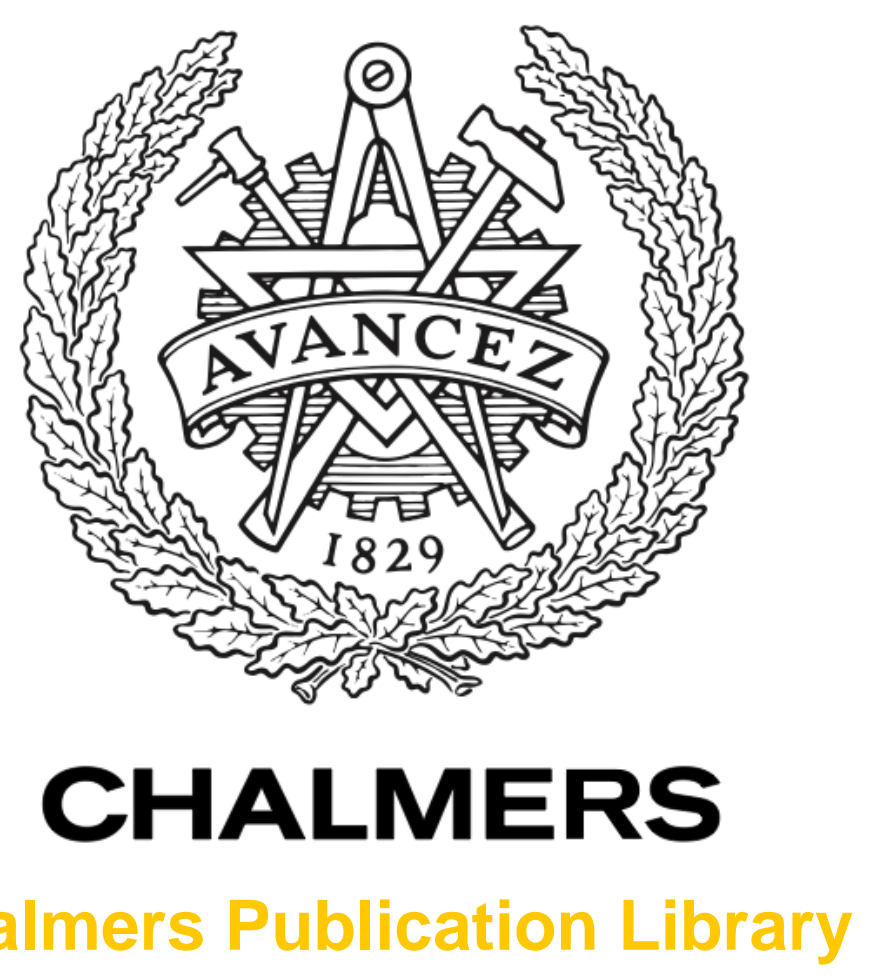

Challmers Publication Library

P-band Polarimetric Model of Vertical Tree Stems on Sloping Ground

This document has been downloaded from Chalmers Publication Library (CPL). It is the author's version of a work that was accepted for publication in:

IEEE International Geoscience and Remote Sensing Symposium (IGARSS)

Citation for the published paper:

Blomberg, E. ; Soja, M. ; Ulander, L. (2014) "P-band Polarimetric Model of Vertical Tree Stems on Sloping Ground". IEEE International Geoscience and Remote Sensing Symposium (IGARSS)

Downloaded from: http://publications.lib.chalmers.se/publication/201983

Notice: Changes introduced as a result of publishing processes such as copy-editing and formatting may not be reflected in this document. For a definitive version of this work, please refer to the published source. Please note that access to the published version might require a subscription.

Chalmers Publication Library (CPL) offers the possibility of retrieving research publications produced at Chalmers University of Technology. It covers all types of publications: articles, dissertations, licentiate theses, masters theses, conference papers, reports etc. Since 2006 it is the official tool for Chalmers official publication statistics. To ensure that Chalmers research results are disseminated as widely as possible, an Open Access Policy has been adopted.

The CPL service is administrated and maintained by Chalmers Library. 


\title{
P-BAND POLARIMETRIC MODEL OF VERTICAL TREE STEMS ON SLOPING GROUND
}

\author{
E. Blomberg ${ }^{1}$, M. J. Soja ${ }^{1}$, and L. M. H. Ulander ${ }^{1,2}$ \\ ${ }^{1}$ Chalmers University of Technology, Göteborg, Sweden \\ ${ }^{2}$ Swedish Defence Research Agency (FOI), Linköping, Sweden
}

\begin{abstract}
A fully polarimetric model is implemented to simulate backscatter from boreal forest. The aim is to correct for topography on a sub-stand level during the recovery of forest properties from P-band SAR data, specifically directed at the upcoming BIOMASS mission. The model incorporates the direct, double-bounce and triple-bounce scattering from tree stems on a sloping ground. Topography is introduced by assigning an independent and arbitrarily oriented local ground plane to each tree. Simulated SAR images are produced from in-situ measurements and a high resolution digital topography model (DTM) based on LiDAR data. These were obtained during BioSAR 2010 together with the corresponding SAR images, which are used for validation.
\end{abstract}

Index Terms-Forestry, scattering, synthetic aperture radar (SAR)

\section{INTRODUCTION}

There is a pressing need of improved mapping of global forest biomass which, due to its importance in Earth's carbon cycle, is one of the key parameters for future climate predictions. This need is reflected in the recent selection of BIOMASS for the European Space Agency's (ESAs) seventh Earth Explorer mission. BIOMASS will use a fully polarimetric and interferometric P-band Synthetic Aperture Radar (SAR) and one of the primary objectives is to provide global data on above ground forest biomass with an accuracy of $<20 \%$ and a resolution of 100-200 m [1].

The high target accuracy will require an advancement of the state of the art for P-band SAR and is subject to an ongoing research effort. Previous studies have found that it is necessary to correct for topographic effects when obtaining boreal forest biomass from the measured backscatter [2-3], with the best model using both the average ground slope and multiple polarizations (HV and the HH/VV ratio) [2]. The results in [3], where the groundstem interaction for vertical stems and an undulating ground surface was computed using a physical-optics approximation, suggested that even the topography on the sub-stand level is of importance for the resulting SAR image.

This paper uses a slightly modified version of the model in [4] to investigate the influence of the detailed topography on the backscatter from hemi-boreal forest and the relative importance of the different polarizations when determining biomass. Data from the BioSAR 2010 experiment is used to provide forest and ground input data as well as polarimetric SAR data for validation of the simulations.

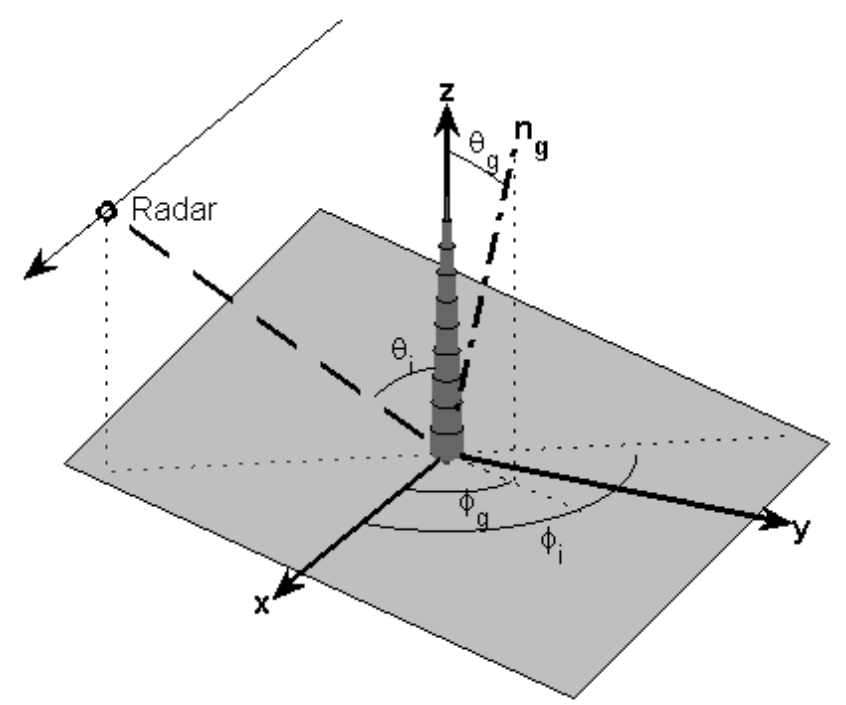

Figure 1: The geometry used, showing incident angles $\theta_{\mathrm{i}}, \phi_{\mathrm{i}}$ and a sloping ground plane with ground angles $\theta_{\mathrm{g}}, \phi_{\mathrm{g}}$ and normal $\mathbf{n}_{\mathrm{g}}$.

\section{METHODOLOGY}

The model simulates the backscatter from a collection of dielectric cylinders above an infinite dielectric half-space using the infinite cylinder approximation. Tree stems are modelled as tapering stacks of 10 cylinders following a profile based on a Norway spruce from [4], see Figure 1 and 2. The stems are scaled to individual height and radius, with an option to use fewer cylinders for smaller trees if desired. 


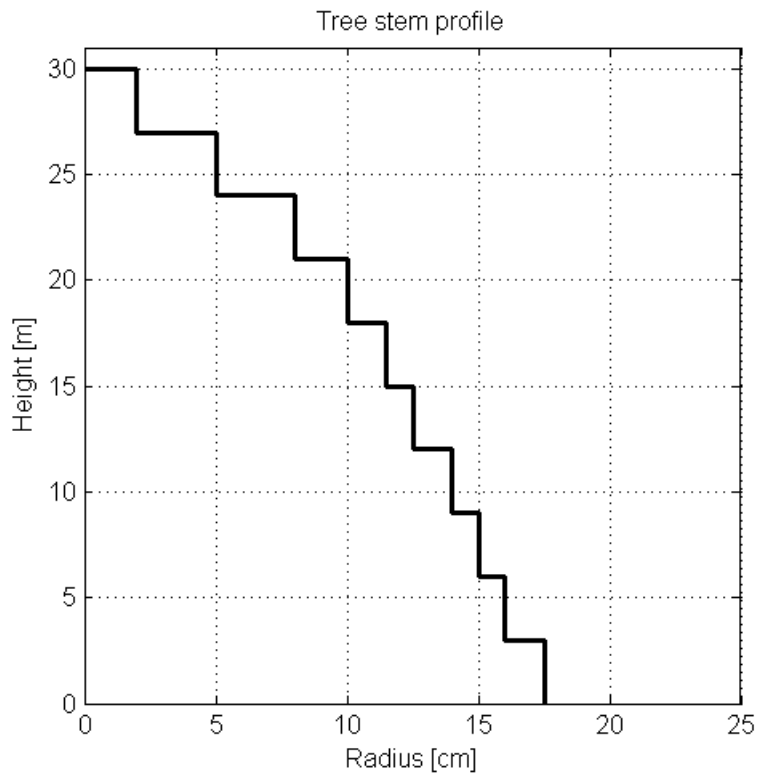

Figure 2. A profile representing a $30 \mathrm{~m}$ high Norwegian spruce using a tapered stack of 10 cylinders. The diameter at breast height (dbh) of the tree is $35 \mathrm{~cm}$.

It is also possible, although not used in this work, to vary the orientation of each cylinder. Cylinder-cylinder interactions such as shadowing or multiple reflections are not included.

A varied topology is approximated with a local ground plane for each cylinder (usually kept the same for all cylinders in each tree), which can be based on a ground model or fitted to a DTM. The specular point is then calculated and is, if within a specified range, used to obtain the double- and triple-bounce contribution in addition to the direct scattering from each cylinder. The incident and scattered waves are separated into polarizations for each part of the calculations, resulting in the possibility to extract the HH, VV and HV components of the backscatter.

SAR images are produced by simulating the response for each tree in the scene separately with a simplified PFA routine followed by coherent addition, averaging and down sampling if required.

\section{BIOSAR2 2010 DATA}

The BioSAR 2010 campaign was a follow up and expansion of BioSAR 2007, again focusing on the hemi-boreal forest site Remnngstorp in the south of Sweden (58 30' N, 13 $40^{\prime} \mathrm{E}$ ). The experiment was funded by ESA to study how forest changes over time (such as growth, thinning, clear cuts and storm damage) are reflected in P-band SAR data as well as topographic effects. See [5] for further details.
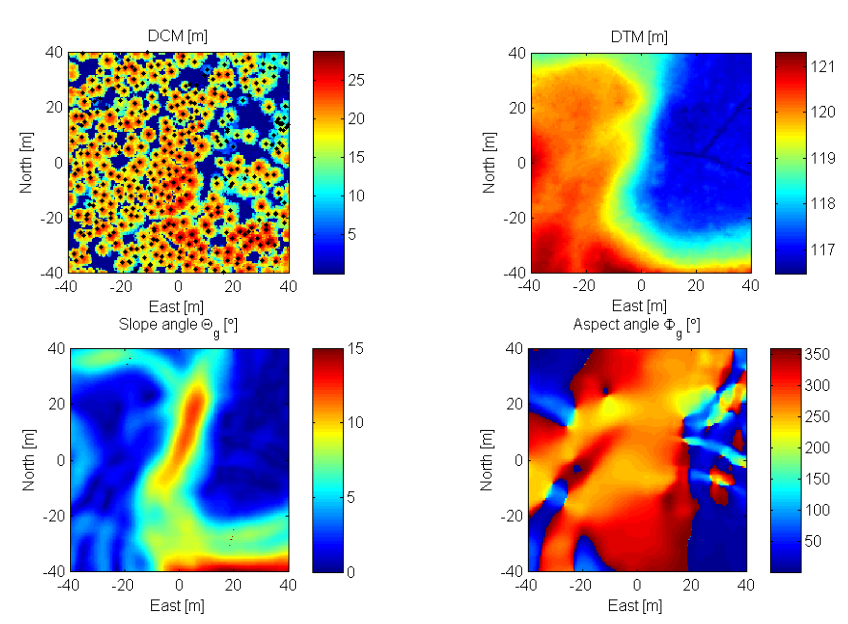

Figure 3. BioSAR 2010 data for plot 1017 ( $80 \mathrm{~m}$ by $80 \mathrm{~m}$ ): The DCM with individual trees marked by black dots (top left) and the DTM (top left). The two angular lines to the right in the DTM are ditches. The local slope (bottom left) and aspect angles (bottom right) were calculated by fitting a plane to the DTM data in a $10 \mathrm{~m}$ by $10 \mathrm{~m}$ square centered on each pixel.

\subsection{In-situ and LiDAR data}

Data from field plot 1017 was chosen for this study, out of seven field plots measuring $80 \mathrm{~m}$ x $80 \mathrm{~m}$ available. Insitu data for these plots include species, individual tree positions and diameters for all trees with a dbh of at least 5 $\mathrm{cm}$ as well as height for a subset of trees. Estimations of biomass, both total and separated by species and structure (stem, branches, needles...), are given as averages for each plot.

LiDAR data collected by the helicopter-mounted TopEye MkIII system from 200 and $400 \mathrm{~m}$ was used to produce a digital topography model (DTM) and a digital canopy model (DCM) with vegetation/structure height above ground. Both the DTM and the DCM were rasterized to a $0.5 \mathrm{~m} \times 0.5 \mathrm{~m}$ resolution [5]. The DTM is in this work used to provide the surface topography as well as the $\mathrm{z}$ position of the stems. The DCM is used to get the height of trees when unavailable as shown by the example data shown in Figure 3.

\subsection{SAR data}

The main focus of BioSAR 2010 was the acquisition of Pband SAR images and 8 different images were acquired on 23 September following the flight paths used in 2007 as closely as possible, with the addition of one heading $\left(270^{\circ}\right)$. The processed P-band bandwidth was $277-443 \mathrm{MHz}$, the incidence angle $24-62^{\circ}$ and the altitude just below $4 \mathrm{~km}$. 


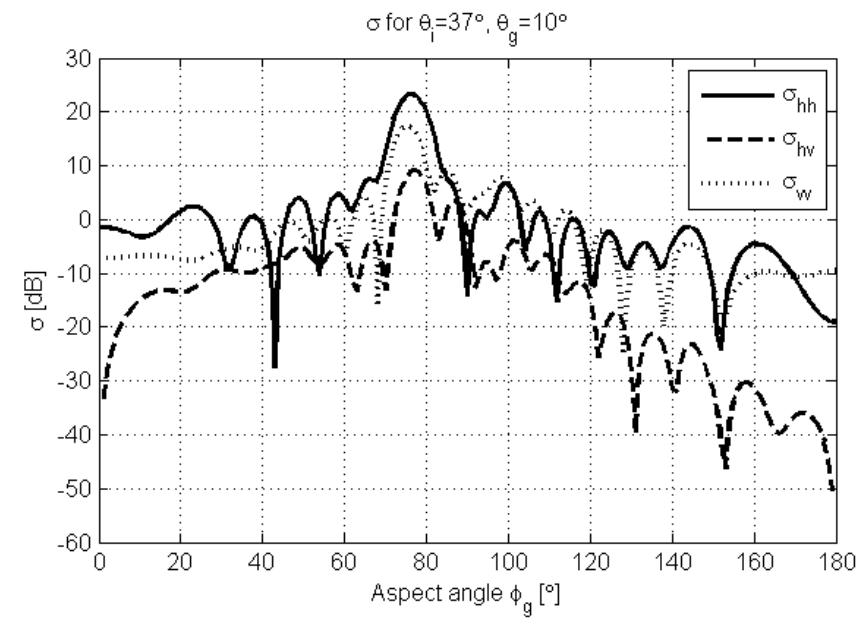

Figure 4. The backscatter from a 10-cylinder single tree with the dimensions specified in Figure 1 and a dielectric permittivity of 12.4-2.1i. The frequency is $435 \mathrm{MHz}$, the incidence angle $37^{\circ}$, the ground slope $10^{\circ}$ (dielectric permittivity $11.0-0.3 i$ ) and the aspect angle is varied from $0^{\circ}$ to $180^{\circ}$.

The end result relevant for this paper was three calibrated images containing $\mathrm{HH}, \mathrm{VV}$ and $\mathrm{HV}$ components of $\sigma^{0}$ from the headings $199^{\circ}, 178^{\circ}$ and $270^{\circ}$, with a subset of plots visible in all three images.

\section{RESULTS}

The results of a representative simulation of a single tree can be seen in Figure 4. The HH and VV components are of the same magnitude and show a similar dependence on the aspect angle except for slopes parallel to the incident direction. The HV component is generally weaker and varies much more with the geometry. This contradicts the claim that $\mathrm{HV}$ is the least affected polarization found in many previous studies; however, a large portion of the HV backscatter might be attributed to other mechanisms (such as scattering of large branches) when the angle between the stem and the ground is close to $90^{\circ}$.

Figure 3 shows that there is an area in the center of plot 1017 with an average slope of about $10^{\circ}$ to the east. The illumination is parallel to this slope for the $178^{\circ}$ flight but at a right angle to it for the $270^{\circ}$ flight. The simulation then suggest that all polarizations should increase for this area, $\mathrm{HH}$ and $\mathrm{VV}$ to the same degree with a stronger effect for HV. This is in good agreement with the actual SAR images for this plot (Figures 5 and 6) that have similar intensity for the flat areas and a marked increase in the central area, especially for HV.

Figure 5 and 6 also show simulated SAR images for plot 1017, using the data displayed in Figure 3 to determine the three dimensional position of the trees and the corresponding ground angles. Each tree was split into 10 cylinders and assumed to be straight and vertical. The $178^{\circ}$ heading (with the radar looking east, i.e. to the right in the
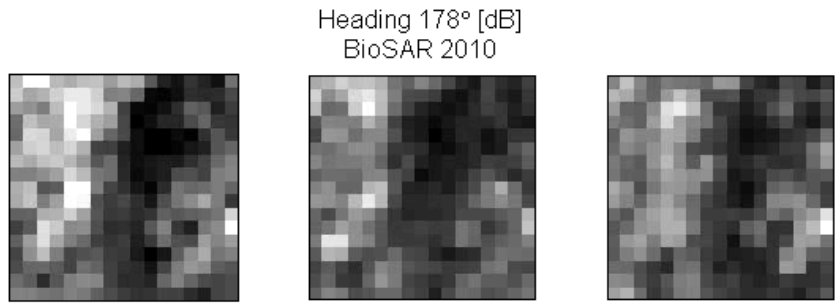

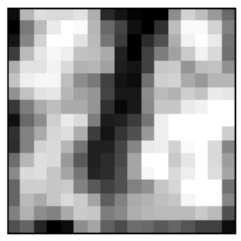

$\mathrm{HH}$

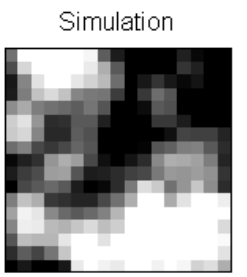

HV

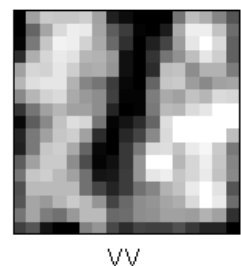

Figure 5. Backscattering amplitude for plot 1017 from the $178^{\circ}$ flight, i.e. looking east. All images are down sampled to $5 \mathrm{~m} \times 5 \mathrm{~m}$ resolution from 81-look equivalent images spanning $10 \mathrm{~dB}$ in amplitude. Top: Measured backscatter for different polarizations. Bottom: Simulated backscatter.

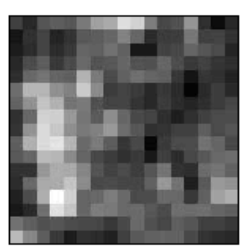

Heading $270^{\circ}[\mathrm{dB}]$ BIOSAR 2010
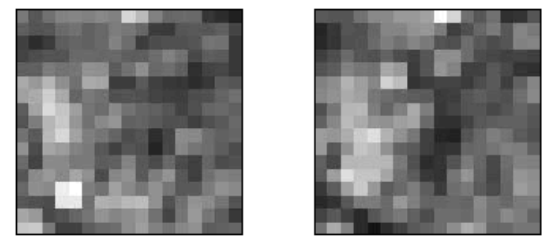

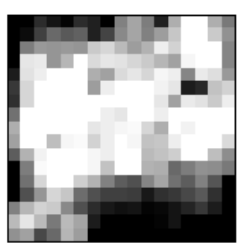

$\mathrm{HH}$

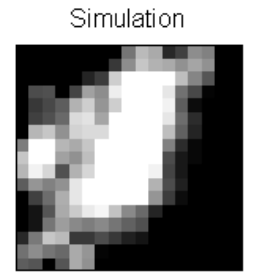

HV

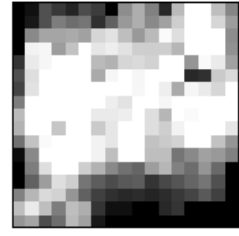

W
Figure 6. Backscattering amplitude for plot 1017 from the $270^{\circ}$ flight, i.e. looking south. All images are down sampled to $5 \mathrm{~m} \times 5 \mathrm{~m}$ resolution from 81-look equivalent images spanning $10 \mathrm{~dB}$ in amplitude. Top: Measured backscatter for different polarizations. Bottom: Simulated backscatter.

image) show a good agreement with the backscatter decreasing significantly on the central slope away from the radar. Also visible in the simulated image is the marked increase in HV backscatter for slopes at close to right angles with the look direction (at the bottom right and top left corners). For heading $270^{\circ}$ (i.e. radar looking south, or down in the image) the model produces a fairly 
homogenous response for the flat areas, but does not display the slightly lower backscatter from the central eastward slope seen for all the polarizations in the actual SAR data. It instead exhibits the theoretically expected stronger $\mathrm{HV}$ backscatter from this region with $\mathrm{HH}$ and $\mathrm{VV}$ being less affected. The simulated images also show a decreased backscatter in the lower right and upper left corners, both areas where the ground is now sloping towards the radar.

\section{CONCLUSIONS}

The model is able to reproduce a large part of the variation attributed to topography seen in the BioSAR P-band SAR images. Further work includes simulating more plots for which data are available as well as a deeper investigation in the contribution of the different scattering mechanisms to the variation in total backscatter.

\section{REFERENCES}

[1] ESA (2012), "Report for Mission Selection: Biomass", ESA SP-1324/1 (3 volume series). Noordwijk, Netherlands: European Space Agency.
[2] M.J. Soja, G. Sandberg, and L.M.H. Ulander, Regression-based Retrieval of Boreal Forest Biomass in Sloping Terrain using P-band SAR Backscatter Intensity Data, IEEE Trans. Geosci. Remote Sensing, vol. 51, no. 5, pp. 2646-2665, 2013

[3] B. Hallberg, G. Smith-Jonforsen, L.M.H. Ulander, and G. Sandberg, "A physical-optics model for double-bounce scattering from tree stems standing on an undulating ground surface," IEEE Transactions on Geoscience and Remote Sensing, vol. 46, no. 9, pp. 2607-2621, 2008.

[4] G. Smith-Jonforsen, L. M H. Ulander, Xianyun Luo, "Low VHF-band backscatter from coniferous forests on sloping terrain," IEEE Transactions on Geoscience and Remote Sensing, vol.43, no.10, pp. 2246-2260, Oct. 2005

[5] L. M. H. Ulander, A. Gustavsson, B. Flood, D. Murdin, P. Dubois-Fernandez, X. Dupuis, G. Sandberg, M. J. Soja, L. E. B. Eriksson, J. E. S. Fransson, J. Holmgren and J. Wallerman, "BIOSAR 2010 Technical Assistance for the Development of Airborne SAR and Geophysical Measurements during the BioSAR 2010 Experiment: Final Report", 2011. ESA contract no. 4000102285/10/NL/JA/ef. 